\title{
PREDIKSI KEBUTUHAN LISTRIK JANGKA PENDEK MENGGUNAKAN MOVING AVERAGE
}

\author{
Emidiana \\ Dosen Tetap Yayasan pada Program Studi Teknik Elektro \\ Fakultas Teknik Universitas PGRI Palembang \\ e-mail:emidianaal@yahoo.com
}

\begin{abstract}
ABSTRAK
Prediksi kebutuhan energi listrik jangka pendek mempunyai peran penting dalam perencanaan sistem tenaga listrik yaitu untuk penjadwalan dan pengaturan pembangkit cadangan. Hal ini nantinya akan berdampak pada kemampuan perusahaan penyedia tenaga listrik dalam menyediakan energi listrik yang handal kepada konsumen, namun tetap ekonomis. Salah satu metode yang dapat digunakan dalam prediksi tersebut adalah Moving Average yang merupakan salah satu metode penyelesaian untuk time series analysis (analisa runtun waktu) Pada penelitian ini dilakukan prediksi beban listrik jangka pendek di wilayah Sumbagsel menggunakan metode Moving Average berbasiskan software SPSS 16. Hasil prediksi yang diperoleh, akan dibandingkan dengan hasil aktual. Dari hasil perhitungan, dapat disimpulkan bahwa rata-rata MAPE hasil prediksi selama satu minggu, menggunakan Moving Average sebesar 4,7817\% masih berada dalam batas toleransi deviasi peramalan beban yang ditentukan oleh PLN yaitu sebesar $\pm 5 \%$.
\end{abstract}

Kata kunci : prediksi kebutuhan listrik, Sumbagsel, Moving Average, SPSS, MAPE

\section{PENDAHULUAN}

Listrik adalah bentuk energi yang paling praktis penggunaannya oleh manusia karena energi listrik tersebut dapat dengan mudah diubah menjadi bentuk energi yang lain misalnya : energi cahaya pada lampu, energi gerak pada motor listrik, dll, sehingga kebutuhan listrik terus meningkat dengan karakteristik pelanggan yang bervariasi. Tenaga listrik tidak dapat disimpan dalam skala besar, sehingga perusahaan penyedia tenaga listrik harus mampu memprediksi kebutuhan listrik pada periode tertentu agar pelayanan kepada pelanggan terjamin kehandalannya namun tetap ekonomis. Oleh karena itu diperlukan metode yang dapat memprediksi kebutuhan listrik dengan hasil yang cukup akurat. Salah satu metode tersebut adalah Moving Average. Pada penelitian ini akan dilakukan prediksi beban listrik untuk wilayah PLN Sumbagsel, dengan menggunakan data runtun waktu (time series) berupa realisasi konsumsi beban listrik wilayah Sumbagsel yang didapat dari PT PLN (Persero) UPB Sumbagsel. Hasil prediksi dengan menggunakan Moving Average kemudian akan dibandingkan dengan beban aktual.

Dalam penelitian ini dilakukan pembatasan masalah sbb:

1. Beban yang akan diprediksi adalah beban listrik jangka pendek dengan menggunakan data-data yang diperoleh selama penelitian.

2. Beban yang akan diprediksi adalah beban daya nyata (MW) yang dikonsumsi pelanggan.

3. Data yang digunakan adalah data beban listrik 24 jam per hari, kecuali hari libur bukan minggu, bulan Ramadhan dan saat kondisi gangguan.

4. Wilayah peramalan beban listrik meliputi wilayah Sumbagsel.

5. Pemrograman Moving Average dilakukan dengan pemrograman SPSS 16.

6. Input data dilakukan secara manual. 


\section{TINJAUAN PUSTAKA}

\section{Prediksi (Peramalan) Beban Listrik}

Perencanaan sistem tenaga listrik yang baik menjadi awal manajemen operasi tenaga listrik yang baik. Salah satu langkah perencanaan adalah peramalan (prediksi) beban listrik. Tidak ada rumus eksak untuk memprediksi beban listrik tersebut. Oleh karena itu diperlukan teknik untuk memprediksi kebutuhan beban ini dengan mengacu pada statistik masa lalu dan berdasarkan analisis karakteristik beban yang lalu. Secara garis besar hari-hari prediksi beban listrik dapat dikelompokkan menjadi hari Senin sampai Kamis, Jumat, Sabtu dan Minggu, juga Hari Raya (Djiteng Marsudi, 2011 : 153).

Berdasarkan kegiatan pemakaiannya, konsumen listrik dapat dibedakan atas : konsumen rumah tangga (perumahan) dengan fluktuasi konsumsi listrik yang cukup besar karena dominan dipakai pada malam hari, konsumen industri dengan fluktuasi konsumsi listrik sepanjang hari akan sama dan konsumen komersil dengan beban puncak yang lebih tinggi pada malam hari. (Daman Suswanto, 2009 :201)

\section{Analisa Runtun Waktu (Time Series Analysis)}

Runtun waktu (time series) adalah suatu himpunan pengamatan yang dibuat secara berurutan dalam suatu waktu atau periode tertentu. Penyusunan data untuk time series diskrit dapat dilakukan dengan 2 cara yaitu

1. Melalui sampling dari runtun waktu kontinu, artinya data yang kontinu diambil sampelnya dalam interval waktu yang sama.

2. Melalui akumulasi suatu peubah dalam suatu waktu tertentu. Misalnya curah hujan yang biasanya diakumulasikan melalui suatu periode waktu tertentu (hari, bulan, dst) (Siana Halim, 2006 : 1)

Peramalan time series : peramalan berdasarkan perilaku data masa lampau untuk diproyeksikan ke masa depan dengan memanfaatkan persamaan matematika dan statistika. (Arna Fariza)

\section{Tipe pola data runtun waktu (time series) terdiri dari :}

1. Gerakan jangka panjang (long time movement)

Gerakan trend jangka panjang adalah suatu gerakan yang menunjukkan arah perkembangan atau kecenderungan secara umum dari deret berkala yang meliputi jangka waktu yang panjang. Umumnya jangka waktu yang digunakan sebagai ukuran adalah sepuluh tahun lebih, ciri gerakan ini kadang-kadang menunjukkan variasi sekuler yang menyerupai garis lurus, yang disebut garis arah (trend line).

2. Gerak musiman (seasonal variation)

Dengan ciri gerakan yang mempunyai pola-pola tetap atau identik dari waktu ke waktu dengan jangka waktu tertentu, gerakan tersebut dapat terjadi karena adanya peristiwa-peristiwa tertentu.

3. Gerak melingkar (siklis)

Gerak ini merupakan variasi rangkaian waktu yang menunjukkan gerakan berayun di sekitar arah atau kurva arah. Lingkaran atau siklik itu bisa bersifat berkala atau tidak.

4. Gerakan acak (random)

Ditandai dengan gerakan yang tak teratur yang disebabkan oleh faktor-faktor di luar dugaan, seperti wabah, gempa bumi, dan sebagainya. (Budiono, 2004)

Beberapa Metode Penyelesaian Analisa Runtun Waktu (Makridakis, dkk, 1999 : 391)

1. Model Autoregressive (AR)

Dengan rumus : $\mathrm{Y}_{\mathrm{t}}=\beta_{0}+\beta_{1} \mathrm{Y}_{\mathrm{t}-1}+\beta_{2} \mathrm{Y}_{\mathrm{t}-2}+\ldots+\beta_{\mathrm{p}} \mathrm{Y}_{\mathrm{t}-\mathrm{p}}+\varepsilon_{\mathrm{t}}$ 
dimana:

$\mathrm{Y}_{\mathrm{t}}=$ series yang stasioner

$\mathrm{Y}_{\mathrm{t}-1}, \mathrm{Y}_{\mathrm{t}-2}=$ nilai lampau series yang bersangkutan

$\beta_{0}, \beta_{1}, \beta_{2}=$ konstanta dan koefisien model

$\varepsilon_{\mathrm{t}}=$ kesalahan peramalan (galat).

\section{Model Moving Average (MA)}

Mempunyai bentuk sebagai berikut : $\mathrm{Y}_{\mathrm{t}}=\mathrm{a}_{0}+\mathrm{e}_{\mathrm{t}}-\mathrm{a}_{1} \mathrm{e}_{\mathrm{t}-1}-\mathrm{a}_{2} \mathrm{e}_{\mathrm{t}-2}-\ldots-\mathrm{a}_{\mathrm{q}} \mathrm{e}_{\mathrm{t}-\mathrm{q}}$ dimana:

$\mathrm{Y}_{\mathrm{t}}=$ Nilai series yang stasioner

$\mathrm{e}_{\mathrm{t}}=$ Kesalahan peramalan (galat)

$\mathrm{e}_{\mathrm{t}-1}, \mathrm{e}_{\mathrm{t}-2}=$ Kesalahan peramalan masa lalu

$\mathrm{a}_{0}, \mathrm{a}_{1}, \mathrm{a}_{2}=$ Konstanta dan koefisien model, mengikuti konvensi

koefisien pada model ini diberi tanda negatif.

\section{Model Autoregressive-Moving Average (ARMA)}

Gabungan dari model Autoregressive (AR) dan Moving Average (MA) dinamakan model autoregressive-moving average (ARMA).

Dengan bentuk umum sebagai berikut: dimana:

$$
Y_{t}=\beta_{0}+\beta_{1} Y_{t-1}+\ldots+\beta_{p} Y_{t-p}+e_{t}-a_{1} e_{t-1}-\ldots-a_{q} e_{t-q}
$$

$\mathrm{Y}_{\mathrm{t}}=$ Nilai series yang stasioner

$\mathrm{Y}_{\mathrm{t}-1}, \mathrm{Y}_{\mathrm{t}-\mathrm{p}}=$ Nilai lampau series yang bersangkutan

$\mathrm{e}_{\mathrm{t}-1}, \mathrm{e}_{\mathrm{t}-\mathrm{q}}=$ Kesalahan masa lampau

$\mathrm{e}_{\mathrm{t}}=$ Kesalahan peramalan

$\beta_{0}, \beta_{1}, \beta_{\mathrm{p}}, \mathrm{a}_{1}, \mathrm{a}_{\mathrm{q}}=$ Konstanta dan koefisien model.

\section{Model Autoregressive Integrated Moving Average (ARIMA)}

Model AR, MA, dan ARMA digunakan untuk data time series yang bersifat stasioner. Untuk data yang tidak stasioner sehingga harus melalui proses differencing sebanyak $d$ kali agar menjadi stasioner. Jika kita menggunakan data time series yang sudah didiferensial sebanyak $d$ kali agar stasioner dan diterapkan pada model $\operatorname{ARMA}(p, q)$, maka persamaan ini akan menjadi model ARIMA $(p, d, q)$.

Notasi yang cukup bermanfaat untuk menggambakan proses differencing adalah operator shif mundur (backward shif) $B$, yang penggunaannya adalah sebagai berikut:

$\mathrm{B} \mathrm{Y}_{\mathrm{t}}=\mathrm{Y}_{\mathrm{t}-1}$

Notasi $B$ yang dipasang pada $Y_{\mathrm{t}}$ yang mempunyai pengaruh menggeser data satu periode ke belakang. Dua penerapan $B$ untuk shif $Y_{t}$ akan menggeser data tersebut dua periode kebelakang sebagai berikut :

$\mathrm{B}\left(\mathrm{B} \mathrm{Y}_{\mathrm{t}}\right)=\mathrm{B}^{2} \mathrm{Y}_{\mathrm{t}}=\mathrm{Y}_{\mathrm{t}-2}$

\section{Mean Absolute Percentage Error (MAPE)}

Mean Absolute Percentage Error (MAPE) merupakan ukuran kesalahan relative. MAPE menyatakan presentase kesalahan hasil peramalan terhadap permintaan actual selama periode tertentu yang akan memberikan informasi presentase kesalahan terlalu tinggi atau terlalu rendah. (Marcelina Rizka Falevy)

$\operatorname{MAPE}(\%)=\frac{1}{N} \sum_{i=1}^{N} \frac{\left|P_{A}^{i}-P_{F}^{i}\right|}{P_{A}^{i}} \times 100 \%$ 
dimana :

$$
\begin{aligned}
& \mathrm{P}_{\mathrm{A}}=\text { beban aktual } \\
& \mathrm{P}_{\mathrm{F}}=\text { beban hasil peramalan } \\
& \mathrm{N}=\text { jumlah data } \\
& \text { (Dinar Atika Sari, 2010) }
\end{aligned}
$$

\section{METODE PENELITIAN}

Program prediksi beban listrik dengan metode Moving Average, menggunakan software SPSS 16 (Abdul Hadi, 2012 : 71)

1. Inputkan data beban listrik per jam selama 16 hari $(16 \times 24$ jam $=384$ data $)$

2. Klik menu Analyze > Time Series > Create Models

3. Isikan Beban_MW ke Dependent Variables, kemudian pada method pilih ARIMA, pada Criteria Model pada Moving Average (q) isi 360, berarti data yang diperhitungkan sebanyak 360 data.

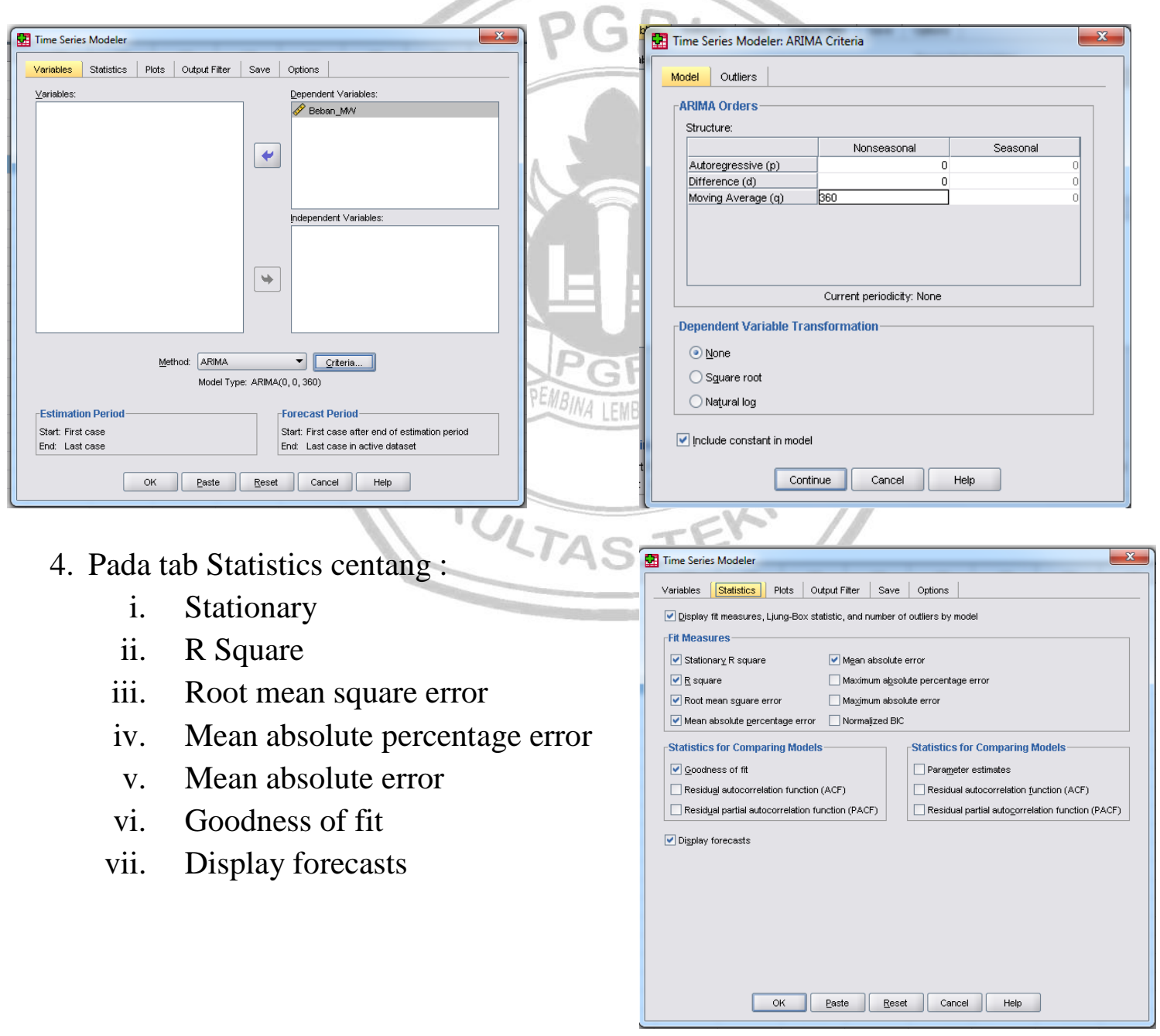


5. Pada tab Statistics centang :

viii. Stationary

ix. R Square

x. Root mean square error

xi. Mean absolute percentage error

xii. Mean absolute error

xiii. Goodness of fit

xiv. Display forecasts

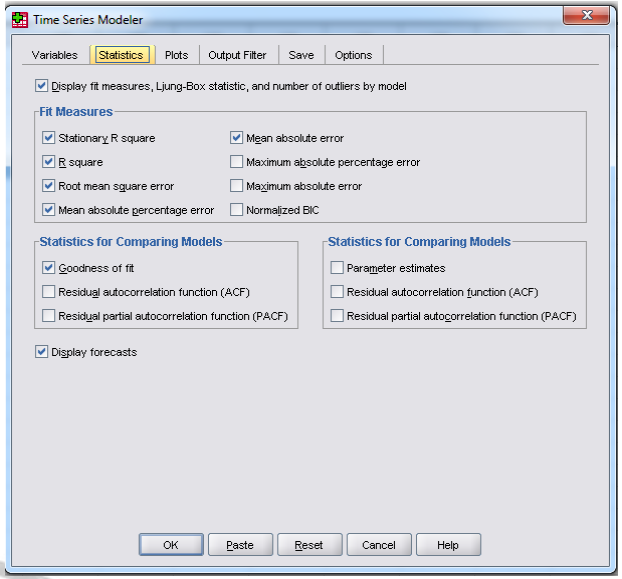

6. Pada tab Statistics centang

xv. Stationary

xvi. R Square

xvii. Root mean square error

xviii. Mean absolute percentage error

xix. Mean absolute error

xx. Goodness of fit

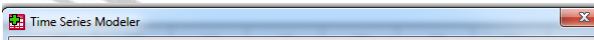

Variables [Statistics $]$ Plots $\mid$ Output Fititer $\mid$ Save $\mid$ options

$\checkmark$ Display ft measures, Liung-Box statisitic, and number of oftilers by model

Fit Measures -

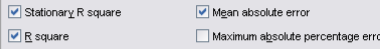

V Root mean sguare error $\square$ Maximum absolute error

V Mean absolite percertags error $\square$ Normalzzed BIC

Statistics for Comparing Models

■ Gloochess of tit

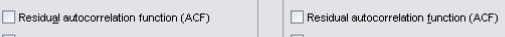

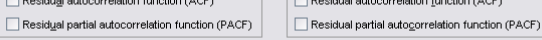

$\checkmark$ Display forecasts

xxi. Display forecasts

oK Paste Beset Cameat Help

7. Pada tab Plots centang

i. Series

ii. Observed values

iii. Forecasts

iv. Fit values

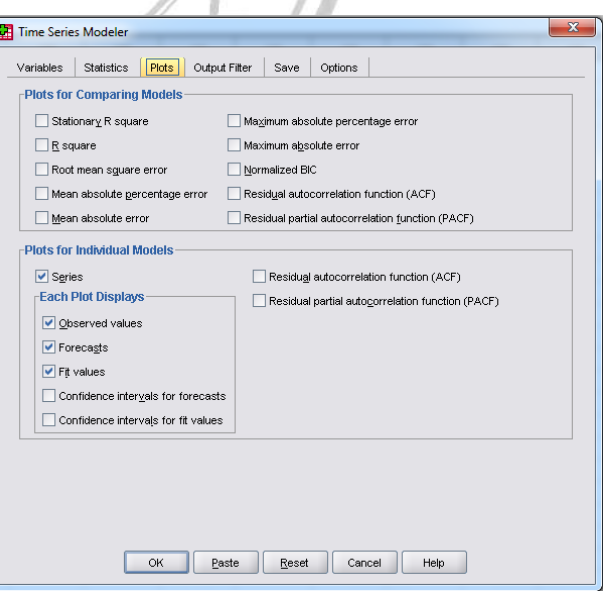


8. Pada tab Save centang

i. Predicted Values

ii. Lower Confidence Limits

iii. Upper Confidence Limits

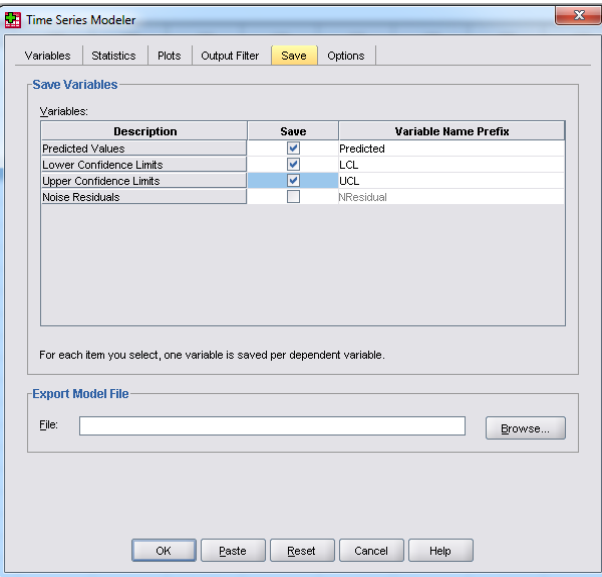

9. Pada tab Save centang

iv. Predicted Values

v. Lower Confidence Limits

vi. Upper Confidence Limits
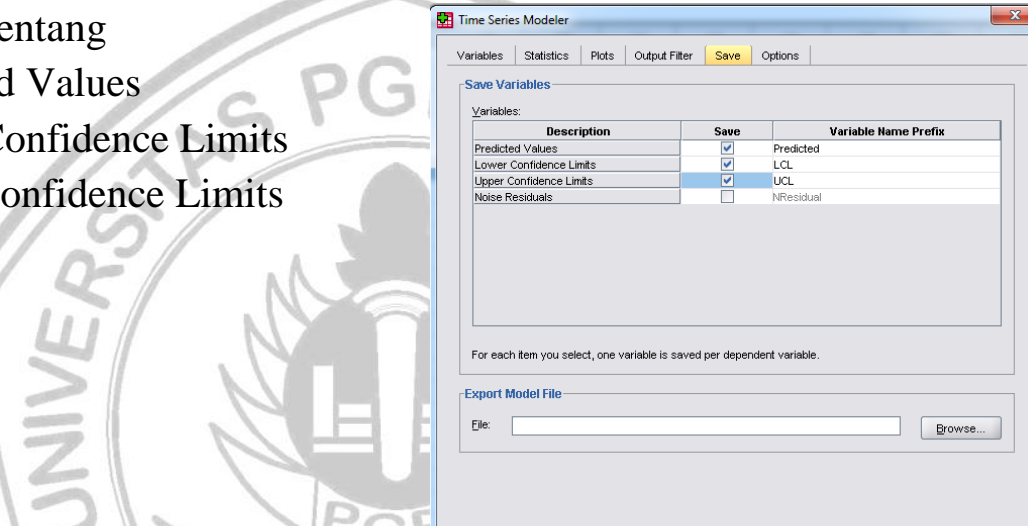

For each htem you select, one variable is saved per dependent variable.

Export Model Fille

Ele:

10. Pada tab Options pilih : First case after end of estimation period through a specified date Pada kotak Observation isi 408

Angka 408 menunjukkan berarti nilai yang akan diprediksi sampai dengan 408

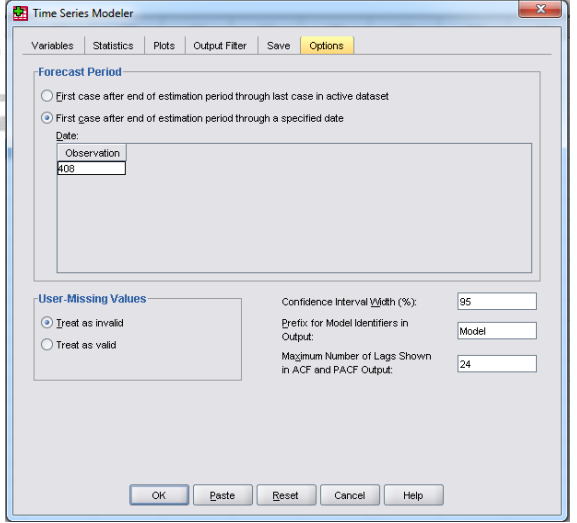

11. Hitung nilai Mean Absolute Percentage Error (MAPE) 


\section{HASIL DAN PEMBAHASAN}

Hasil Prediksi Beban Listrik Selama Seminggu dari Senin (19 September 2012) sampai Minggu (25 September 2012)

Tabel 1. Perbandingan Hasil Prediksi dan

Tabel 2. Perbandingan Hasil Prediksi dan Beban Aktual Hari Senin, 19 September 2012

Beban Aktual Hari Selasa, 20 September 2012

\begin{tabular}{|c|c|c|c|c|c|c|c|c|}
\hline Jam & Aktual & MA & Error MA (\%) & & Jam & Aktual & MA & Error MA $(\%)$ \\
\hline 01.00 & 862.7 & 889.2 & 3.0682 & & 01.00 & 896.3 & 848.9 & 5.2905 \\
\hline 02.00 & 820.7 & 862.8 & 5.1285 & & 02.00 & 842.2 & 849.8 & 0.9024 \\
\hline 03.00 & 804.3 & 860.8 & 7.0208 & & 03.00 & 850.8 & 839.8 & 1.2952 \\
\hline 04.00 & 813.1 & 877.7 & 7.9476 & & 04.00 & 868.4 & 897.6 & 3.3625 \\
\hline 05.00 & 897.8 & 956.6 & 6.5458 & & 05.00 & 943.1 & 997.5 & 5.7682 \\
\hline 06.00 & 994.6 & 1032.5 & & & 06.00 & $1,026.7$ & 1034.8 & 0.7880 \\
\hline 07.00 & 876.1 & 913.6 & 4.2803 & & 07.00 & 922.8 & 963.0 & 4.3563 \\
\hline 08.00 & 846.5 & 904.8 & & & 08.00 & 804.3 & 934.1 & 16.1397 \\
\hline 09.00 & 853.2 & 911.2 & 6.8042 & & 09.00 & 814.8 & 934.8 & 14.7275 \\
\hline 10.00 & 889.3 & 933.5 & 4.9655 & & 10.00 & 872.3 & 930.7 & 6.6949 \\
\hline 11.00 & 891.5 & 926.6 & 3.9418 & & 11.00 & 947.4 & 930.7 & 1.7586 \\
\hline 12.00 & 917.0 & 920.9 & 0.4242 & & 12.00 & 938.2 & 911.3 & 2.8682 \\
\hline 13.00 & 928.8 & 918.1 & 1.1499 & & 13.00 & 951.6 & 897.2 & 5.7157 \\
\hline 14.00 & 936.9 & 931.1 & 0.6222 & & 14.00 & 964.5 & 895.4 & 7.1672 \\
\hline 15.00 & 889.1 & 967.3 & 8.7954 & & 15.00 & 963.8 & 919.7 & 4.5776 \\
\hline 16.00 & 926.8 & 955.4 & 3.0870 & & 16.00 & $1,008.1$ & 938.5 & 6.9078 \\
\hline 17.00 & 940.7 & 1007.7 & 7.1246 & & 17.00 & $1,033.4$ & $1,022.1$ & 1.0944 \\
\hline 18.00 & $1,182.1$ & 1189.7 & 0.6455 & & 18.00 & $1,168.4$ & $1,190.0$ & 1.8513 \\
\hline 19.00 & $1,342.7$ & 1288.0 & 4.0717 & & 19.00 & $1,334.8$ & $1,256.6$ & 5.8586 \\
\hline 20.00 & $1,361.2$ & 1290.4 & 5.1999 & & 20.00 & $1,135.8$ & $1,250.2$ & 10.0693 \\
\hline 21.00 & $1,276.5$ & 1245.3 & 2.4465 & & 21.00 & $1,080.2$ & $1,202.4$ & 11.3107 \\
\hline 22.00 & $1,164.5$ & 1153.8 & 0.9171 & & 22.00 & $1,057.1$ & $1,118.0$ & 5.7660 \\
\hline 23.00 & $1,071.2$ & 1058.1 & 1.2202 & & 23.00 & 943.4 & $1,005.1$ & 6.5413 \\
\hline 24.00 & 956.5 & 963.5 & 0.7308 & & 24.00 & 860.8 & 905.9 & 5.2381 \\
\hline \multicolumn{3}{|c|}{ MAPE (\%) } & 4.0346 & & \multicolumn{3}{|c|}{ MAPE (\%) } & 5.6688 \\
\hline
\end{tabular}

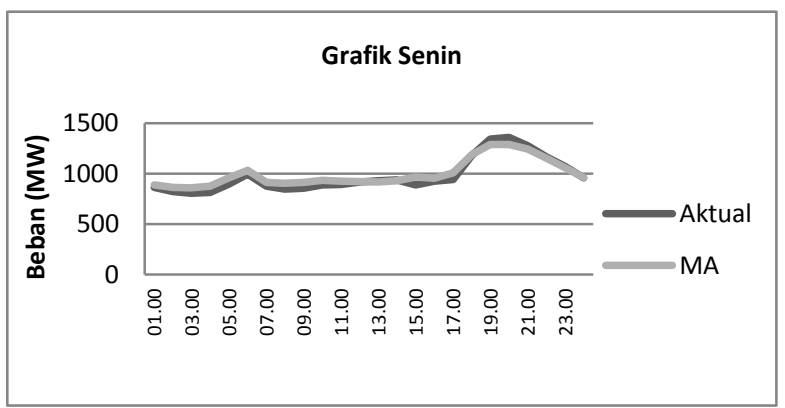

Gambar 7. Grafik Perbandingan Hasil Prediksi dan Beban Aktual Hari Senin, 19 September 2012

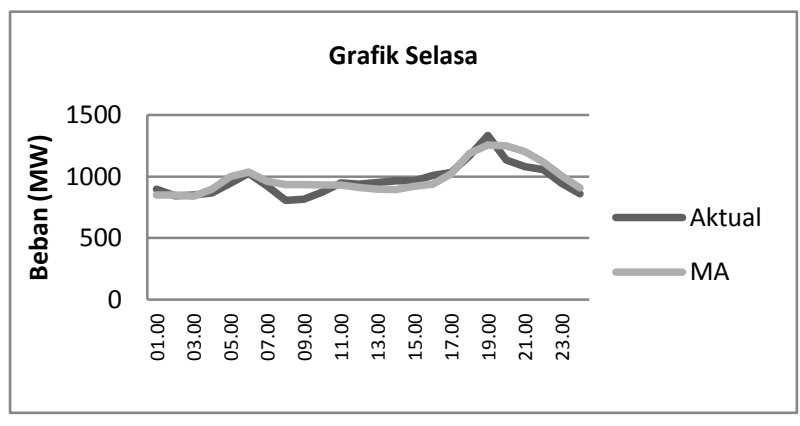

Gambar 8. Grafik Perbandingan Hasil Prediksi dan Beban Aktual Hari Selasa, 20 September 2012 
Tabel 3. Perbandingan Hasil Prediksi dan Beban Aktual Hari Rabu, 21 September 2012

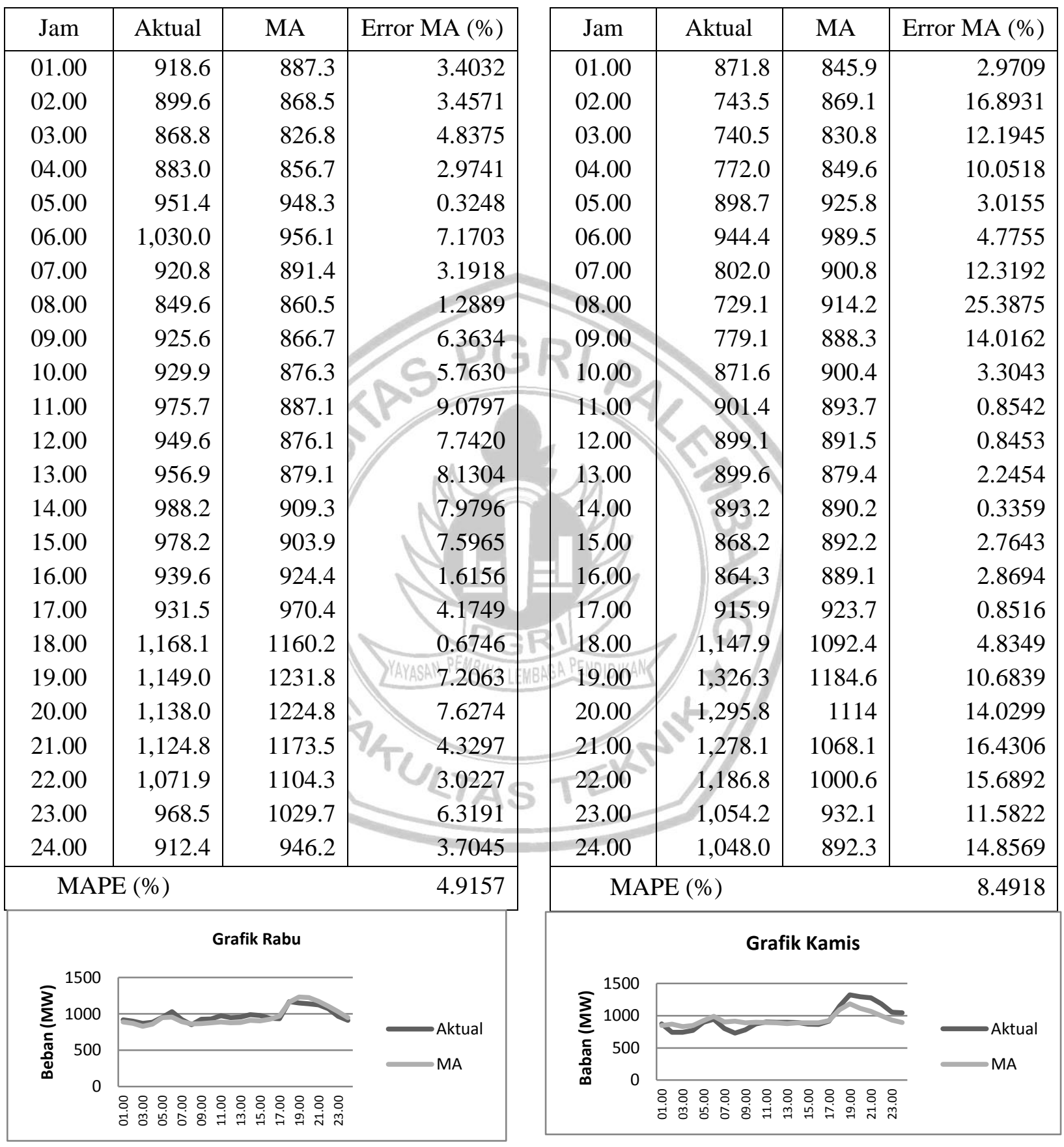

Gambar 9. Grafik Perbandingan Hasil Prediksi dan Beban Aktual Hari, Rabu 21 September 2012
Tabel 4. Perbandingan Hasil Prediksi dan Beban Aktual Hari Kamis, 22 September 2012
Gambar 10. Grafik Perbandingan Hasil Prediksi dan Beban Aktual Hari, Kamis 22 September 2012 
Tabel 5. Perbandingan Hasil Prediksi dan Beban Aktual Hari Jumat, 23 September 2012

Tabel 6. Perbandingan Hasil Prediksi dan Beban Aktual Hari Sabtu, 24 September 2012

\begin{tabular}{|c|c|c|c|c|c|c|c|c|}
\hline Jam & Aktual & MA & Error MA $(\%)$ & & Jam & Aktual & MA & Error MA $(\%)$ \\
\hline 01.00 & 910.6 & 929.1 & 2.0316 & & 01.00 & 861.6 & 878.4 & 1.9475 \\
\hline 02.00 & 836.4 & 901.4 & 7.7714 & & 02.00 & 843.8 & 878.3 & 4.0911 \\
\hline 03.00 & 824.3 & 841.8 & 2.1255 & & 03.00 & 819.4 & 869.9 & 6.1656 \\
\hline 04.00 & 822.0 & 845.6 & 2.8735 & & 04.00 & 838.2 & 868.3 & 3.5960 \\
\hline 05.00 & 904.0 & 901.2 & 0.3141 & & 05.00 & 920.1 & 932.5 & 1.3521 \\
\hline 06.00 & 983.1 & 954.9 & 2.8645 & & 06.00 & 953.3 & 938.5 & 1.5484 \\
\hline 07.00 & 895.5 & 889.4 & 0.6812 & & 07.00 & 842.1 & 858.8 & 1.9807 \\
\hline 08.00 & 817.4 & 894 & 9.3685 & & 08.00 & 798.2 & 857.6 & 7.4377 \\
\hline 09.00 & 901.8 & 954.2 & 5.8141 & & 09.00 & 874.4 & 852.9 & 2.4599 \\
\hline 10.00 & 896.0 & 960 & 7.1488 & & 10.00 & 887.3 & 889.1 & 0.2074 \\
\hline 11.00 & 888.1 & 975.7 & 9.8625 & & 11.00 & 919.6 & 907.0 & 1.3669 \\
\hline 12.00 & 893.0 & 949 & 6.2769 & & 12.00 & 914.1 & 920.2 & 0.6651 \\
\hline 13.00 & 881.1 & 914.7 & 3.8158 & 8 & 13.00 & 892.0 & 914.1 & 2.4776 \\
\hline 14.00 & 859.3 & 926.7 & 7.8411 & & 14.00 & 870.3 & 921.9 & 5.9278 \\
\hline 15.00 & 881.8 & 898.6 & 1.9110 & & 15.00 & 843.0 & 912.9 & 8.2944 \\
\hline 16.00 & 883.4 & 915 & 3.5806 & & 16.00 & 883.5 & 925.7 & 4.7788 \\
\hline 17.00 & $1,020.6$ & 950.9 & 6.8275 & & 17.00 & 911.5 & 969.5 & 6.3655 \\
\hline 18.00 & $1,190.8$ & 1136.1 & 4.5968 & $\frac{1}{4 B}$ & 18.00 & $1,129.3$ & $1,119.8$ & 0.8404 \\
\hline 19.00 & $1,337.5$ & 1223.5 & 8.5227 & & 19.00 & $1,258.2$ & $1,219.2$ & 3.1012 \\
\hline 20.00 & $1,252.5$ & 1201.4 & 4.0791 & & 20.00 & $1,228.5$ & $1,189.2$ & 3.1967 \\
\hline 21.00 & $1,200.5$ & 1169.5 & 2.5823 & & 21.00 & $1,132.7$ & $1,137.6$ & 0.4344 \\
\hline 22.00 & $1,094.1$ & 1090.2 & 0.3601 & 5 & 22.00 & $1,026.1$ & $1,044.0$ & 1.7465 \\
\hline 23.00 & 989.0 & 1026.5 & 3.7917 & & 23.00 & 959.9 & 963.1 & 0.3355 \\
\hline 24.00 & 913.4 & 959.7 & 5.0713 & & 24.00 & 905.4 & 874.6 & 3.3997 \\
\hline \multicolumn{3}{|c|}{ MAPE (\%) } & 4.5880 & & \multicolumn{3}{|c|}{ MAPE (\%) } & 3.0715 \\
\hline
\end{tabular}

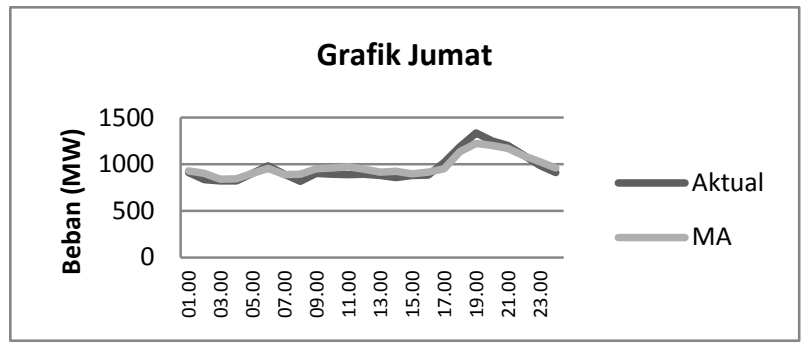

Gambar 11. Grafik Perbandingan Hasil Prediksi dan Beban Aktual Hari Jumat, 23 September 2012

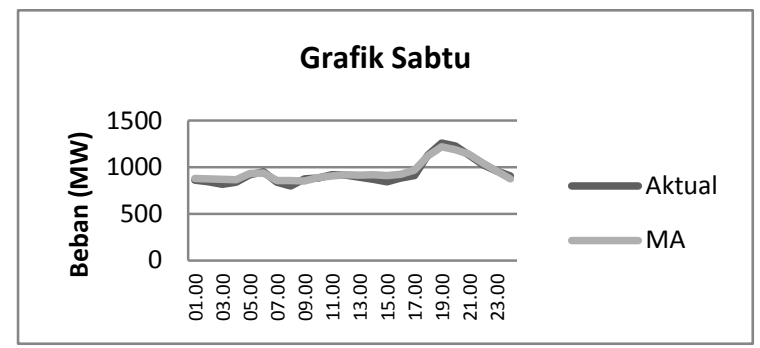

Gambar 12. Grafik Perbandingan Hasil Prediksi dan Beban Aktual Hari Sabtu, 24 September 2012 
Tabel 7. Perbandingan Hasil Prediksi dan Beban Aktual Hari Minggu, 25 September 2012

\begin{tabular}{|c|c|c|c|c|c|c|}
\hline Jam & Aktual & MA & Error MA (\%) & & & \\
\hline 01.00 & 871.7 & 862.3 & 1.0784 & & 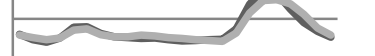 & Aktual \\
\hline 02.00 & 825.8 & 842.4 & 2.0102 & 营 500 & & MA \\
\hline 03.00 & 804.4 & 825 & 2.5609 & 0 & & \\
\hline 04.00 & 839.3 & 839.7 & 0.0500 & & 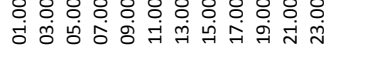 & \\
\hline 05.00 & 928.8 & 907.2 & 2.3256 & & & \\
\hline 06.00 & 932.9 & 917.2 & 1.6850 & Gambar 7. & . Grafik Perbandingan & Hasil Prediksi \\
\hline 07.00 & 878.7 & 868.1 & 1.2075 & & Aktual Hari Minggu, & , 25 September \\
\hline 08.00 & 851.7 & 850.9 & 0.0939 & & & \\
\hline 09.00 & 842.7 & 849.6 & 0.8152 & & & \\
\hline 10.00 & 835.3 & 864.1 & 3.4479 & & & \\
\hline 11.00 & 841.2 & 856.9 & 18664 & & & \\
\hline 12.00 & 824.8 & 844.4 & 2.3825 & & & \\
\hline 13.00 & 815.0 & 837.2 & 2.7290 & & & \\
\hline 14.00 & 819.0 & 827.2 & 1.0025 & & & \\
\hline 15.00 & 824.0 & 818.4 & 0.6796 & & & \\
\hline 16.00 & 829.2 & 810.1 & 2.3011 & & & \\
\hline 17.00 & 917.5 & 881.7 & 3.9050 & & & \\
\hline 18.00 & $1,123.0$ & $1,049.7$ & 6.5272 & & & \\
\hline 19.00 & $1,245.4$ & $1,153.8$ & 7.3551 & & & \\
\hline 20.00 & $1,212.9$ & $1,161.2$ & 4.2641 & & & \\
\hline 21.00 & $1,081.3$ & $1,126.7$ & 4.2035 & & & \\
\hline 22.00 & 968.6 & $1,038.4$ & 7.2019 & & & \\
\hline 23.00 & 895.3 & 922.8 & 3.0681 & & & \\
\hline 24.00 & 845.0 & 862.6 & 2.0792 & 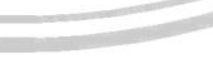 & & \\
\hline \multicolumn{3}{|c|}{ MAPE (\%) } & 2.7017 & & & \\
\hline
\end{tabular}

Sehingga didapat tabel rata-rata MAPE, error minimum dan error maksimum selama 1 minggu tersebut, seperti pada tabel berikut :

Tabel 8. Rata-rata MAPE, error minimum dan error maksimum Moving Average (MA)

\begin{tabular}{|l|c|c|c|}
\hline Hari & MAPE (\%) & Error minimum (\%) & Error maksimum (\%) \\
\hline Senin & 4.0346 & 0.4242 & 8.7954 \\
\hline Selasa & 5.6688 & 0.7880 & 16.1397 \\
\hline Rabu & 4.9157 & 0.3248 & 9.0797 \\
\hline Kamis & 8.4918 & 0.3359 & 25.3875 \\
\hline Jumat & 4.588 & 0.3141 & 9.8625 \\
\hline Sabtu & 3.0715 & 0.2074 & 8.2944 \\
\hline Minggu & 2.7017 & 0.0500 & 7.3551 \\
\hline Rata-rata & 4.7817 & 0.3492 & 12.1306 \\
\hline
\end{tabular}


MAPE terbesar terjadi pada hari kamis, yaitu 8,4918\% dengan error maksimumnya 25,3875\%. Pada hari Kamis, mulai pukul $19.00-24.00$, pukul $02.00-04.00$, pukul $07.00-09.00$, tercatat penggunaan listrik jauh menurun dari hari-hari biasanya, hal ini bisa juga disebabkan terjadinya pemadaman di daerah-daerah tertentu. MAPE terkecil terjadi pada hari Minggu yaitu sebesar 2,7017\% dengan error minimum $0,0500 \%$ dan error maksimum $7,3551 \%$.

\section{KESIMPULAN}

1. Rata-rata MAPE hasil prediksi menggunakan MA sebesar $4,7817 \%$.

2. Rata-rata error minimum MA nilainya $0,3492 \%$.

3. Rata-rata error maksimum MA adalah $12,1306 \%$

4. MAPE peramalan menggunakan MA masih dalam batas toleransi deviasi peramalan beban yang ditentukan oleh PLN yaitu sebesar $\pm 5 \%$.

\section{DAFTAR PUSTAKA}

1. Siana Halim, Diktat Time Series Analysis, 19 Januari 2006, xa.yimg.com/kq/groups/68173314/.../Timeseries+Analysis.pdf..., diakses 2 November 2016

2. Makridakis/Wheelwright/McGEE. Metode dan Aplikasi Peramalan Binarupa Aksara: Jakarta, 1999

3. Arna Fariza, Soft Computation Reseach Group, Electronic Engineering Polytechnic Institute of Surabaya, arna.lecturer.pens.ac.id/Topik.../Peramalan\%20Time\%20Series.pdf, diakses 2 November 2016

4. Marcelina Rizka Falevy, M.Zen Samsono H,S.T,M.Sc, Akuwan Saleh, SST, Sistem Peramalan Harga Sembako Berbasis Moving Average Dengan Brew Platform Sebagai Mobile Interface. https://www.pens.ac.id/uploadta/downloadmk.php?id=1343, diakses 2 Juni 2016

5. Dinar Atika Sari, Peramalan Kebutuhan Beban Jangka Pendek Menggunakan Jaringan Syaraf Tiruan Backpropagation, eprints.undip.ac.id/25280/1/ML2F002572.pdf, diakses 3 Juni 2011

6. Djiteng Marsudi, Pembangkitan Energi Listrik, Penerbit Erlangga, Edisi Kedua, 2011

7. Abdul Hadi, Hartatik, Getut Pramesti, Aplikasi SPSS Dalam Saham, Penerbit PT Elex Media Komputindo, 2012

8. Boediono dan Wayan, K, Teori dan Aplikasi Statistika dan Probabilitas, Bandung : P.T Remaja Rosdakarya Offset, 2004.

9. Daman Suswanto, Sistem Distribusi Tenaga Listrik, edisi 1, 2009, www.cs.unsyiah.ac.id/ frdaus/.../tugas2/data/kulit-muka1.pdf, diakses 2 November 2016 